\title{
Identification of optimal countermeasures strategies in agriculture in the long term after the ChNPP accident
}

\author{
S.V. Fesenko, A.Yu. Pakhomov, A.V. Panov and N.I. Sanzharova \\ Russian Institute of Agricultural Radiology and Agroecology, 249020 Obninsk, Russia
}

\begin{abstract}
The approach for the estimation of the effectiveness of countermeasure strategies in the long term after the Chernobyl accident, based on the classification of farms and rural settlements by site specific factors governing transfer of radionuclides to agricultural products is described. It has been found that application of remediation options on the territory of Russia will be necessary at decreasing scales up to 2050. Settlements and collective farms located on the contaminated territory were divided into 18 categories based on the contamination density of ${ }^{137} \mathrm{Cs}$ and in the first case on annual internal doses and on risk of the overestimation of standards, restricting the use of agricultural products (in the second case). To derive remediation strategies for these categories, 29 settlements and 108 representative farms were studied for which extensive radioecological data were gathered. Eight main remedial actions were considesed for each farm (settlement). The effectiveness of each of these actions (applied alone or in combination with each other) in terms of averted doses as well as cost of 1 man-Sv averted was estimated. For each category of the farms the ranking of rehabilitation options and the time periods when their application would be of importance were justified and estimated. Five remediation strategies (including site specific approach justified in the study), different in effectiveness and cost, were compared to provide the information for making decision on retabilitation of contaminated territories in the long term after the ChNPP accident.
\end{abstract}

\section{INTODUCTION}

Radioact ive contamination of agricultural land and products is one of the main factors responsible for the radioactive risk level and scale of countermeasures necessary for the mitigation of consequences of radioactive contamination and countermeasures in agriculture hold a central position in the system of measures for liquidating consequences of the Chernobyl accident. Overall, the introduction of countermeasures has practically led by 1996 to a minimum production of food stuffs which do not meet the radiological standards, as well as to a noticeable reduction in the exposure dose to the population living in the affected regions (Fesenko et al., 1994). The long term after the Chernobyl accident is marked by a severe economic crisis in Russia, which is responsible for a sharp decrease in financing of agricultural countermeasures. Simultaneously changes are being made from the temporary (accidental) to "non-accidental" (more stringent) standards on the permissible irradiation of the public and permissible radionuclide concentration in foodstuffs. This led to the need to improve of the approach to the countermeasures application.

In 1996-2000, the Directorate General for Environment of the European Commission supported two projects dealing with the optimisation of remediation strategies of contaminated territories resulting from the Chemobyl accident. The main aim of these activities co-ordinated by GSF was to help the CIS countries that are the most affected by the accident to take appropriate countermeasures and develop new policies in the field of site remediation (Jacob et al., 2000). A new approach for the identification of optimal countermeasure options was suggested and practical results important for CIS countries were achieved.

The objective of this paper was to present the progress in the studies in the field of the optimal countermeasures strategies selection in the long term after the ChNPP accident and it includes the results achieved within last two years lapsed after these projects.

\section{APPROACH FOR THE SELECTION OPTIMAL COUNTERMEASURES STRATEGIES}

In deciding on optimal strategy of countermeasures, two cohorts of the population are to be identified for whom countermeasures for reducing internal exposure doses may have their own peculiarities. The first cohort is the population living in the affected area and consuming foodstuffs produced in this 
area (private sector). The second one is the population living outside the affected area but consuming foodstuffs produced in the contaminated area (collective sector). As the main criterion for the estimation of need to apply countermeasures for the first category one should consider the level of annual exposure of the population of $1 \mathrm{mSv}$ year $^{-1}$ (act "On radiation safety"). The criterion for the second cohort will be the excess of the non-accidental standard for agricultural products (milk, beef, pork) and as a consequence a decrease in the collective dose from the consumption of contaminated products. Worth noting is a marked difference in the aims of countermeasure application for the identified population categories. While in the first case countermeasures are aimed directly at the dose reduction to the population, the objective in the second case is to reduce dose export from the affected regions.

The term "countermeasures strategy" was defined in the current study as a site-specific combination of different countermeasures proposed for the whole period when intervention in areas subjected to contamination is necessary. Because of a large variety of environmental conditions and exposure pathways which depend on soil properties, agricultural practices, contamination, etc. It is practically impossible to define directly countermeasures strategies that could be applied to the contaminated territory. This suggests subdivision of the contaminated collective farms and settlements to the category with similar site-specific factors governing contamination of agricultural products and exposure of the population and comparison of countermeasure strategies taking into account the total effect of its application for the whole period when each strategy is proposed.

In deciding on optimal strategy of countermeasures, two cohorts of the population are to be identified for whom countermeasures for reducing internal exposure doses may have their own peculiarities. The first cohort is the population living in the affected area and consuming foodstuffs produced in this area (private sector). The second one is the population living outside the affected area but consuming foodstuffs produced in the contaminated area (collective sector). As the main criterion for the estimation of need to apply countermeasures for the first category one should consider the level of annual exposure of the population of $1 \mathrm{mSv}$ year $^{-1}$. The criterion for the second cohort will be the excess of the nonaccidental standard for agricultural products. Worth noting is a marked difference in the aims of countermeasure application for the identified population categories. While in the first case countermeasures are aimed directly at the dose reduction to the population, the objective in the second case is to reduce dose export from the affected regions. Therefor, the general objectives of the agricultural land restoration can be formulated as follows:

- To provide opportunities for the production of agricultural products which can be used without any restrictions;

- To provide radiation safety standards for people involved in agricultural production.

Formally, justification of countermeasure strategies in agriculture could be presented in several steps:

1. Evaluation of the need for restoration and classification of eollective farms settlements taking into account specific features in contamination of agricultural products and internal dose forming;

2. Selection of settlements and collective farms which are representative for each category and detailed study of exposure pathways the factors governing agricultural products contamination;

3. Assessment of the effectiveness of different countermeasure and remediation options under particular conditions;

4. Comparative analysis and ranking of the restoration options for settlements (collective farms) with similar site-specific conditions;

5. Comparative analysis and ranking of the countermeasures taking into account the total effects of their implementation.

When developing a strategy for remadiation is aimed at obtaining of maximal effect from the applied countermeasures with minimal investments, necessary to take into account the factors governing efficiency of their use. Among the major factors responsible for the formation of internal doses and consequently effectiveness of measures for reducing internal exposure doses are fallout density, features of agricultural land (eg. soil properties, peculiarities of previously used measures, etc.), local products (milk, potato) used in production and contribution of forest products to the human diet.

Considering the above peculiarit ies, farms and rural settlements located in the Chernobyl affected area have been classified by ${ }^{137} \mathrm{Cs}$ contamination density: 
- agricultural land used for production of fodder and animal grazing (collective sector). For classification the following gradations were used: $37-185 \mathrm{kBq} \mathrm{m}, 185-555 \mathrm{kBq} \mathrm{m}^{-2}, 555-740 \mathrm{kBq}^{-2}$, above $740 \mathrm{kBq} \mathrm{m}^{-2}$.

- territory of settlements (private sector). The following criteria for settlements classification by ${ }^{137} \mathrm{Cs}$ contamination density were chosen: $37-185 \mathrm{kBq} \mathrm{m}^{-2}, 185-370 \mathrm{kBq} \mathrm{m}{ }^{-2}, 370-555 \mathrm{kBq} \mathrm{m}^{-2}$ and above $555 \mathrm{kBq} \mathrm{m}^{-2}$.

Collective farms were classified by risk (probability) of production of milk with ${ }^{137} \mathrm{Cs}$ content above non-accidental radiation standards $\left(50 \mathrm{~Bq} \mathrm{l}^{-1}\right)$. The following division of farms by risk was made: $0,0-10,10-50,50-90$, above $90 \%$. Rural settlements were classified by internal exposure doses to the population as settlements with the mean annual internal dose of below $0.5,0.5-1$, above $1 \mathrm{mSv}$.

With such a classification it may be expected that for farms of the collective sector and settlements belonging to each of the identified categories the excess of standard levels in products (collective sector) and the annual exposure limit $1 \mathrm{mSv}^{-1}$ (private sector) will be determined by similar factors, thereby allowing the development of differential countermeasure strategies and consideration of local conditions for their application. Hence, the suggested classification provides a means for the implementation of site-specific system of necessary countermeasures.

Eight countermeasure options different from point of view effectivenes, cost and exposure pathways were used for the identification of optimal remediation strategies (Table 1).

Table I. List of countermeasures considered in the study

\begin{tabular}{|l|c|c|c|c|c}
\hline \multicolumn{1}{|c|}{ Countermeasures action } & Farms & $\begin{array}{c}\text { Settle- } \\
\text { ments }\end{array}$ & Reduction factor & Cost, Euro & $\begin{array}{c}\text { Cost per in- } \\
\text { habitants, Euro }\end{array}$ \\
\hline Time \\
period
\end{tabular}

Justification of the data used for the estimation of the effectiveness of countermeasures options considered and appropriate cost is given elsewhere (Jacob et al, 2000).

\section{RESULTS}

\subsection{Classification of settlement and farms located on the territory effected by ChNPP accident}

Classification of settlements and farms located on the contaminated territory has shown that 662 thousand people are living in Russia in 4662 rural settlements located at the territory with contamination by ${ }^{137} \mathrm{Cs}$ above $37 \mathrm{kBq} \mathrm{m}^{-2} .307$ settlements mainly located in Bryansk region with the population 48000 . people are characterised by annual dose above $1 \mathrm{mSv}$. About $80 \%$ of these settlements can be classified as forest settlements where contribution of forest products (berries and mushrooms) should be taken into account.

Table 2. Number of Russian rural settlements in area with contamination above $37 \mathbf{~ k B q ~ m}^{-2}$ after the Chemobyl accident and population living in these settlements

\begin{tabular}{|c|c|c|c|c|}
\hline \multirow{2}{*}{$\begin{array}{l}\text { Internal dose } \\
\left(\mathrm{mSv} \mathrm{a}^{-1}\right)\end{array}$} & \multicolumn{4}{|c|}{${ }^{137} \mathrm{Cs}$ activity per unit area ( $\mathrm{kBq}$ per $\left.\mathrm{m}^{2}\right)$} \\
\hline & $37-185$ & $185-370$ & $370-555$ & $>555$ \\
\hline$<0.5$ & $\overline{0}$ & 6 & 22 & 2 \\
\hline $0.5-1$ & 0 & 28 & 70 & 84 \\
\hline$>1$ & 7 & 12 & 11 & 65 \\
\hline
\end{tabular}

More than 600 collective farms are located on this territory which produce agricultural products. At present they mainly produce products which is in accordance with requirements of non-accidental radiation standards and all produced products, excepting for milk are in accordance with the requirements 
of non-accidental standards. However, in 55 farms located in south-west part of Bryansk region the risk of exceeding $50 \mathrm{~Bq} \mathrm{I^{-1 } 1 3 7} \mathrm{Cs}$ content in milk is above $10 \%$ that disturbs economical life in this area.

Table 3. Classification of collective farms located on the toritory subjected to contamination after the ChNPP accident by riskiness of milk production with ${ }^{137} \mathrm{Cs}$ content above $50 \mathrm{~Bq}{ }^{\top} \mathrm{I}$ (based on 1996 data)

\begin{tabular}{|c|c|c|c|c|}
\hline \multirow[t]{2}{*}{ Risk of exceeding $50 \mathrm{~Bq} \mathrm{I}^{-177} \mathrm{Cs}$ content in milk } & \multicolumn{4}{|c|}{${ }^{13} \mathrm{Cs}$ activity per unil area, $\mathrm{kBq} / \mathrm{m}^{2}$} \\
\hline & $37-185$ & $185-555$ & $555-740$ & $>740$ \\
\hline $0-0,1$ & 7 & 15 & 0 & 0 \\
\hline $0,1-0,5$ & 5 & 18 & 4 & 2 \\
\hline $0,5-0,9$ & 1 & 7 & 2 & 4 \\
\hline$>0,9$ & 1 & 2 & 3 & 6 \\
\hline
\end{tabular}

As a whole these data show the scale of radiation problems on territories contaminated after the ChNPP accident.

\subsection{Analysis of exposure pathways and factors governing contamination of agricultural products}

To estimate the factors governing exposure of population (including influence of countermeasures previously applied to dose reduction) and to derive remediation strategies for considered categories 27 settlements (18 forest and 9 non-forest) and 104 collective farm were selected for which radioecological information was gathered.

It has been found that in the settlements located far from forest contribution of milk to internal dose varied from 45.6 to $76.6 \%$ (geometric average is $62.5 \%$ ). The contribution from forest products in these settlements was between 1.2 and $16.0 \%$ (average - 5.6\%). In most cases, milk is also the main doseforming product in the settlements located near forest. Its contribution to internal dose is, however, significantly lower (23-75\%, geometric average is $48.9 \%$ ), and that from forest products (mainly mushrooms) is higher than for the non-forest settlements $(4.8-48.9 \%$, geometric mean is $22.2 \%)$. In general, the above data show that the application of countermeasures providing a decrease in the radionuclide content in milk remains the most effective way to reduce internal dose, however in some case high concentration of ${ }^{137} \mathrm{Cs}$ in forest products should be also taken into account.

The data obtained has shown that radiological situation in the most contaminated settlements was formed under influence of countermeasure application and annual internal doses in such settlements are 2-3 times less than it would be expected. It has been also confirmed that properties of soils are the main factor determining the contamination of milk in long term after the ChNPP accident (Fig 1).
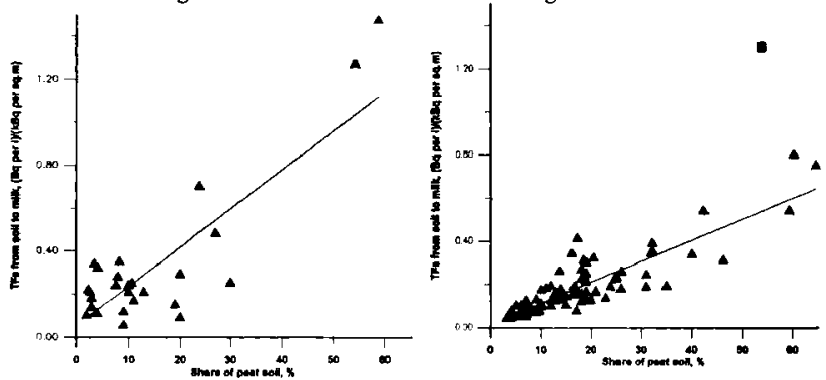

Figure 1. Dependence of $T$ values from soil to milk on the proportion of peat soils in Russian selected setilement (A) and collective farms (B).

The data given in Fig. 1 A show that for the settlements far from forests, the $T_{a g}$ values from soil to milk can be described by a linear dependence on the proportion of peat soils around settlements, occurred also for dependence of aggregated $T_{\text {ag }}$ from soil to milk produced in collective sector (Fig $1 B$ ). For forest 
settlements, this dependence is not so pronounced, which can be explained by the contribution to internal dose of forest food, which would not be a effected by properties of soil near settlements.

When analyzing factors governing ${ }^{137} \mathrm{Cs}$ transfer to milk it should be also noted that no clear correlation is observed between the milk contamination levels and ${ }^{137} \mathrm{Cs}$ land contamination which is connected with the use of countermeasures and properties of soils used for fodder production and cartle grazing.

\subsection{Ranking of countermeasure options for settlements and collective farms with similar site-} specific conditions

Based on the classification of farms and settlements, combinations of protective and remediation measures were formed providing the obtaining of products that meet standards and reduction in the exposure level to below $1 \mathrm{mSv}_{\text {year }}{ }^{-1}$ for different zones identified during classification. All the countermeasures were arranged by the criterion such as the cost of dose averted from the countermeasures use (cost of 1 man-Sv). A set of countermeasures was considered as sufficient when it ensured the production of foodstuff's in compliance with non-accidental radiation standard for milk (50 $\left.\mathrm{Bq} \mathrm{r}^{-1}\right)$ (collective sector) and reduction in the exposure level, below $1 \mathrm{mSv} \mathrm{year}^{-1}$ (private sector). The optimal combinations of these countermeasures were determined for each of the identified categories of farms (settlements) and for different time periods after the accident (address strategy).

Table 4. Strategy of site-specific rehabilitation of farms located in the Chemobyl affected area

\begin{tabular}{|c|c|c|c|c|}
\hline \multirow{2}{*}{$\begin{array}{c}\text { Risk of exceeding } \\
50 \mathrm{~Bq} \mathrm{I}^{-1}{ }^{133} \mathrm{Cs} \\
\text { content in milk } \\
\end{array}$} & \multicolumn{4}{|c|}{${ }^{137} \mathrm{Cs}$ contamination density of fodder lands, $\mathrm{kBq} / \mathrm{m}^{2}$} \\
\hline & $37-185$ & $185-555$ & $555-740$ & $>740$ \\
\hline$a-0,1$ & RI $80 \%$ & RI 80\% & - & - \\
\hline $0,1-0,5$ & RI $100 \%$ & RI $70 \% ;$ RI + PB $15 \%$ & RI 75\%; RI+PB 25\% & RI 35\%; Rl+PB 65\% \\
\hline $0,5-0,9$ & $\mathrm{RI}+\mathrm{PB} 100 \%$ & $\mathrm{RI}+\mathrm{PB} \quad 100 \%$ & $\mathrm{RI} 20 \% ; \mathrm{RI}+\mathrm{PB} \mathbf{8 0 \%}$ & $\begin{array}{c}\mathrm{RI} 50 \% ; \mathrm{R} \mathrm{I}+\mathrm{PB} 30 \% \\
\mathrm{RI}+\mathrm{PB}+\mathrm{GC} 20 \%\end{array}$ \\
\hline$>0,9$ & $\mathrm{RI}+\mathrm{PB} 100 \%$ & $\begin{array}{c}\mathrm{RI}+\mathrm{PB} 40 \% \\
\mathrm{RI}+\mathrm{PB}+\mathrm{GC} 60 \% \\
\end{array}$ & $\mathrm{RI}+\mathrm{PB} 30 \% ; \mathrm{RI}+\mathrm{PB}+\mathrm{GC} 70 \%$ & $\mathrm{RI}+\mathrm{PB}+\mathrm{GC} 100 \%$ \\
\hline
\end{tabular}

Table 5. Strategy of site-specific rehabilitation for nual settlements.

\begin{tabular}{|c|c|c|c|c|}
\hline \multirow{2}{*}{$\begin{array}{ll}\text { Internal } & \text { dose } \\
\left(\mathrm{mSv} \mathrm{a}^{-1}\right)\end{array}$} & \multicolumn{4}{|c|}{${ }^{37} \mathrm{Cs}$ activity per unit area $\left(\mathrm{kBq}_{\mathrm{q}}\right.$ per $\left.\mathrm{m}^{2}\right)$} \\
\hline & $37-185$ & $185-370$ & $370-555$ & $>555$ \\
\hline 0,5 & $=$ & - & $\overline{\mathrm{R}} 100 \% ; \overline{\mathrm{PB}} 50 \%$ & RI $100 \% ; \mathrm{PB} 50 \%$ \\
\hline $0,5-1$ & $\begin{array}{c}\mathrm{RI} 100 \% ; \mathrm{PB} \\
30 \%\end{array}$ & RJ 100\%; PB 50\% & RJ $100 \%$; PB 80\%; MF 15\% & $\mathrm{SM}+\mathrm{DS} 100 \%, \mathrm{MF}+\mathrm{PB}$ \\
\hline$>1$ & $\begin{array}{c}100 \% ; \mathrm{PB} \\
50 \%\end{array}$ & $\begin{array}{c}\mathrm{RI}+\mathrm{PB} 100 \% \\
\mathrm{MF}+\mathrm{FP}+\mathrm{RM} 50 \%\end{array}$ & SM+DS $100 \% ; \mathrm{MF}+\mathrm{PB}$ & $\mathrm{SM}+\mathrm{DS} 100 \% ; \mathrm{MF}+\mathrm{PB}$ \\
\hline
\end{tabular}

\subsection{Comparative analysis of the countermeasures strategies}

For a comparative analysis of possible actions aimed at rehabilitation of collective farms, 6 strategies of countermeasure application have been chosen:

Strategy A. No countermeasures (option do nothing);

Strategy B. Application of countermeasures in the 1996-2000 scales;

Strategy C. Application of Prussian blue on a necessary scale;

Strategy D. Application of Prussian blue in periods when an increased content of radionuclides is noted in products (critical periods) in all the farms where risk of SanPin 2.3.2.560-96 excess is above $5 \%$;

Strategy E. A system of organizational and agrotechnical measures for every farm with the account of local features of animal farming.

As an alternative strategy F - site-specific countermeasures strategy was considered (Table 4).

For the remediation of rural settlements, 5 strategies were considered:

Strategy A. No countermeasures (option do nothing);

Strategy B. Application of countermeasures in the 1996- scales;

Strategy $C$. The strategy based on radical improvement of lands;

Strategy D. Combined application of radical improvement and Prussian blue;

Strategy E. Site-specific strategy (Table S). 
Overall, the set of strategies considered covers all possible options from full cessation of the use of countermeasures to their application on scales necessary to obtain products in accordance with the existing standards starting from 2003 (Fig. 2A) and to reduce exposure doses to the population up to $1 \mathrm{mSv}$ starting from 2001 (Fig. 2B).
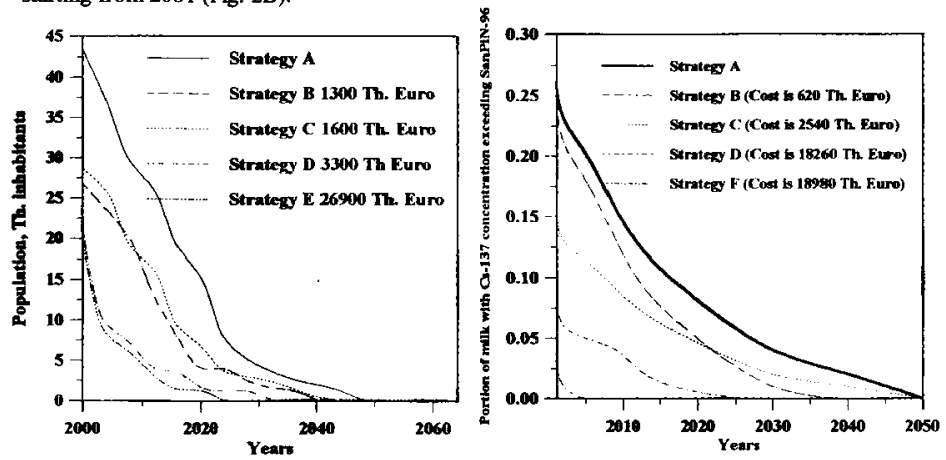

Figure 2. Dynamies of reduction in the fraction of milk with ${ }^{137} \mathrm{Cs}$ content above radiation standards (A) the number of rural residents in setticments with mean annual exposure dose above $1 \mathrm{mSv}$ (B) using different strategies and costs of courntermeasures.

The data presented in Fig. 2 show that the quickest (by 2003) transfer to "non accidental" standards is possible within strategy $\mathrm{F}$. Fairly effective by this criterion is strategy $\mathrm{C}$ based on the use of Prussian Blue. Not so effective are strategies B and D. In the first case the share of products that meet the standards will be achieved in 2025 and for strategy D in 2020 .

Within the use of site-specific countermeasure strategy in rural settlements, except for the three most contaminated groups of settlements, it will be possible as early as in 2001 to achieve a decrease in the annual exposure dose to the population of below $1 \mathrm{mSv}$. On the most affected districts (shaded in the figure) in the framework of the address strategy, a step-by-step approach is proposed to the rehabilitation of territories consisting in decontamination of a settlement area along with the introduction (retaining) of restrictions on private cattle management. On the time period when it is possible to achieve decrease in the total dose to the population up to the kvel below $1 \mathrm{mSv}$ with agricultural countermeasures, restrictions on private cattle management should be lifted and agricultural countermeasures should be applied.

Overall, the obtained results allow the conclusion that application of countermeasures in a long term period after the accident of the ChNPP, on considerable territories of Russia countermeasures will be necessary an large scales, which shows a need for optimisation of countermeasure implementation. Even in the long-term after the ChNPP accident, application of countermeasures on the most contaminated territory will require considerable expenses. The data presented show that even in a long term after the Chernobyl accident the existing possibilities of application of agricultural countermeasures are still efficient thereby providing a return in a short period of time of the contaminated regions to usual practice of farming.

\section{References}

Fesenko S.V., Alexakhin R.M., Spiridonov S.I. and Sanzharova N.I. Dynamics of ${ }^{137}$ Cs concentration in agricultural production in areas of Russia subjected to contamination after the accident at the Chernobyl Nuclear Power Plant. Radiation Protection Dostmetry, 60(2) (1995). 155-166

Jacob P., Fesenko S.V., Schotola C., Gering F., Alexakhin, R., Firsakova S., Sanzharova N.I. et al. Remediation strategies for contaminated territories resulting from the Chernobyl accident. EUR report 19266. 2000. - 123 pp. 